\title{
A EDUCAÇ̃̃O PROFISSIONAL BRASILEIRA DOS ANOS 1920 AOS 1950 NA ESCRITA DE FRANCISCO MONTOJOS (1900-1981)
}

\author{
BRAZILIAN PROFESSIONAL EDUCATION FROM THE 1920S TO THE 1950S IN THE WRITING OF FRANCISCO
} MonTOJOS (1900-1981)

\begin{abstract}
José Geraldo Pedrosa*
jgpedrosa@uol.com.br

RESUMO: O texto tem como temática de fundo a educação profissional (EP) no Brasil, dos anos 1920 a 1950, com relevo para a atuação e a escrita do engenheiro-educador Francisco Montojos, que atuou na EP do Governo Federal de 1927 a 1961. Nas décadas de 1930 e 1940, o governo e lideranças do empresariado industrial envolveram-se com a redefinição das instituições e pedagogia da EP. Esse processo, marcado pela sistematização de ideias, disputas e mudanças, envolveu intelectuais e implicou na escrita de textos. O artigo identifica ideias em circulação, disputas e grupos de aliados. Situa a circulação de ideias do movimento Escola Nova no ambiente da EP, com destaque para a pedagogia dos trabalhos manuais. A empiria vasculhou fontes primárias, entre as quais, textos de Montojos. De modo auxiliar, examinou, também, textos de outros intelectuais do círculo, como Lourenço Filho, Corinto da Fonseca e Roberto Mange. As questões e o tratamento dos achados foram inspirados nos termos da história dos intelectuais.
\end{abstract}

PALAVRAS CHAVE: Educação Profissional, História, Intelectuais, Representações.

ABSTRACT: The text has professional education (PE) as its background thematic in Brazil from the 1920 s to the 1950s, with an emphasis on the performance and writing of engineer-educator Francisco Montojos, who acted on the PE of the Federal Government from 1927 to 1961. In the decades of 1930s and 1940, the government and industrial business leaders became involved in the redefinition of PE institutions and pedagogy. This process marked by the systematization of ideas, disputes and changes, involved intellectuals and implied in writing of texts. The article identifies ideias in circulation, disputes and groups of allies. It places the circulation of ideas from the "New School" movement in the PE environment, with contrast on the pedagogy of manual works. Empiricism searched primary sources, including texts by Montojos. In an auxiliary way its also examined texts by other intellectuals in the circle, such as Lourenço Filho, Corinto da Fonseca and Roberto Mange. The questions and the treatment of the findings were inspired in terms of the history of intellectuals.

KEYWORDS: Professional Education, History, Intellectuals, Representations.

\section{Introdução}

Nesses mais de cem anos que se passaram desde que Nilo Peçanha criou, em 1909, as Escolas de Aprendizes Artífices, portanto, desde que se tornou política republicana para a formação do trabalhador nacional, a educação profissional (EP) no Brasil, cresceu e passou por mudanças significativas, nem sempre contínuas. Nesse tempo, deixou de ser educação para o trabalho e tornou-se educação profissional. A moral cedeu espaço para a técnica;

*Doutorado em Educação pela Pontifícia Universidade Católica de São Paulo (PUC-SP); Pós-doutorado em Geografia Humana pelo Instituto de Geociências da Universidade Federal de Minas Gerais (IGC-UFMG). Professor no Programa de Pós Graduação em Educação Tecnológica do Centro Federal de Educação Tecnológica de Minas Gerais (PPGET-CEFET-MG). 
como público-alvo as crianças foram substituídas por jovens e adultos; o isolamento entre as escolas deu lugar às redes ou sistemas nacionais; o recrutamento exclusivo na pobreza deu lugar à psicotécnica e seus testes para a alocação das pessoas na divisão técnica do trabalho; o sentido social de evitar a vadiagem e a marginalidade foi substituído pelo sentido econômico e mercantil e a escala do ensino deixou de ser artesanal para tornar-se industrial, acontecimento que exigiu padronização de cursos, de métodos e de materiais didáticos.

Todo esse movimento que envolveu constituição, instituição e expansão da EP no Brasil demandou pessoas para pensarem no formato e no estatuto das redes de instituições; elaborarem propostas e participarem das disputas que envolvessem gente do governo, do empresariado e de instituições civis da educação; proporem políticas públicas e recursos orçamentários; representarem o Brasil em fóruns internacionais, mediarem e gerirem acordos com outros países; comandarem redes de escolas, coordenarem quadros administrativos, ministrarem seminários etc.

Esse artigo tem origem em investigações cuja finalidade é identificar intelectuais que atuaram na EP brasileira nas décadas de 1920 a 1950, período no qual o Brasil avançou na industrialização, experimentou crescimento urbano e massificação, regulamentou o trabalho e a EP, elevando-a ao nível secundário, instituiu o ensino industrial - escolas técnicas e o Serviço Nacional de Aprendizagem Industrial (SENAI) - e celebrou acordos e convênios com os Estados Unidos da América (EUA) voltados para a formação de professores de cultura técnica ${ }^{1}$.

A concepção de intelectual aqui adotada, bem como os modos de estudá-lo são provenientes do francês Jean-François Sirinelli (1996), com aportes da brasileira Ângela de Castro Gomes $(1999,2016)$ e do português Justino Magalhães (2016). Sirinelli salienta duas acepções de intelectual: "uma ampla e sociocultural, englobando os criadores e os 'mediadores' culturais, [...] outra mais estreita, baseada na noção de engajamento." (SIRINELLI, 1996, p. 242). Na primeira acepção estão o jornalista, o escritor, o professor do ensino médio e o cidadão erudito. Na segunda acepção, a referência é "a noção de

\footnotetext{
${ }^{1}$ As expressões "professores de oficina" e "professores de cultura técnica" estão utilizadas por Montojos nos escritos dos tempos da Comissão Brasileiro-americana de Educação Industrial - CBAl, notadamente nos textos de apresentação dos livros "Psicologia para professores do ensino industrial" e "Metodologia do Ensino Industrial", de 1949.
} 
engajamento na vida da cidade como ator, [...] testemunha ou consciência." (SIRINELLI, 1996, p. 243). Para Gomes (2016), o intelectual é um importante elo na circulação de ideias e a história dos intelectuais passa pela relação entre o intelectual e o acontecimento. $\mathrm{O}$ intelectual, em determinado momento, atua, testemunha e elabora uma consciência (representação) dos acontecimentos desse mesmo momento. Esses atores, concomitantemente, "inserem-se no campo cultural mais abrangente do qual são contemporâneos, e nele procuram demarcar fronteiras capazes de lhes assegurar identidades individuais e coletivas." (GOMES, 1999, p. 11).

O foco do artigo é sobre o intelectual Francisco Belmonte Montojos, sua atuação, escrita e representações sobre a educação profissional em escala industrial no Brasil dos anos 1920 a 1950. Montojos nasceu em Porto Alegre (RS) em 29 de novembro de 1900 e formou-se em engenharia civil pela Escola de Engenharia de Porto Alegre, em 1925. Ingressou no Governo Federal em 1927, no ensino profissional e técnico e, em 1934, passou a atuar diretamente no ensino industrial, como superintendente. Foi diretor do Ensino Industrial do Ministério da Educação e Saúde Pública (MESP) por longo período, de 1937 a 1949 e de 1955 a 1961, tendo sido também superintendente da Comissão BrasileiroAmericana de Educação Industrial (CBAI) por dois mandatos entre 1946 e 1949 e 1955 a 1961.

O artigo, ao situar a atuação e a escrita de Montojos, enfatiza dois pontos. Um é sobre a sua posição acerca das ideias de origem anglo-americana de EP que circulavam no Brasil da época. O outro é referente a uma disputa ocorrida nos anos 1930 e 1940, entre governo e empresários, referente ao lugar de pertencimento, ao financiamento e ao modus operandi da EP. Montojos atuou diretamente nesses acontecimentos que envolveram, entre outros intelectuais, Lourenço Filho, Joaquim Faria Góes Filho, Celso Suckow da Fonseca, João Luderitz, Leon Renault, Roberto Mange, Roberto Simonsen, Euvaldo Lodi, Anísio Teixeira, Paschoal Lemme e outros.

Magalhães (2016, p. 301) afirma que a "a educação-instituição e a escrita da educação são sistemas de representação.". Isso significa que a representação da educação faz indagações, entre outras fontes, à escrita da educação e que esse processo de "intelecção do educacional é difícil fora da historicidade.". A pesquisa vasculhou fontes primárias, entre as quais, textos de Montojos produzidos à época. De modo auxiliar 
examinou também textos de outros intelectuais do círculo, como Lourenço Filho, Corinto da Fonseca e Roberto Mange. O artigo identifica ideias em circulação, disputas e grupos de aliados. Situa a circulação de ideias do movimento Escola Nova no ambiente da EP, com destaque para a pedagogia dos trabalhos manuais.

Esse retorno ao passado da EP tem também uma inspiração arendtiana. É que, segundo Hannah Arendt (2016), na incerteza ou na crise é conveniente indagar o passado e nele buscar compreender as questões primárias, em busca de um estranhamento das questões do presente e suas perspectivas.

\section{Francisco Montojos e as questões de seu tempo}

A atuação e a escrita e Montojos são significativas para um entendimento do processo constituinte das instituições de ensino industrial no Brasil. Montojos era homem, branco e filho de famílias bem estabelecidas. Nos anos aqui em questão, a constituição da educação profissional (EP), no âmbito do Governo Federal, era assunto exclusivo de homens, de empresários e de brancos. Entre os protagonistas da EP, seja nas comissões de trabalho dos anos 1920 e 1930 que atuaram na remodelação e, depois, na constituição do SENAI e da rede de escolas técnicas federais, seja no comando das instituições, seja na superintendência de acordos internacionais dos anos 1940 em diante, não foram identificados registros da presença de mulheres, de trabalhadores, nem de negros. Foram homens brancos e abastados que delinearam a formação do trabalhador industrial e urbano no Brasil. Entre eles estava Francisco Montojos.

Mas, a figura de Montojos era mais ampla e aberta do que seus lugares de origem e atuação. Ele foi, a um só tempo: engenheiro, industrialista, burocrata, educador, intelectual e memorialista da EP; talvez exatamente nessa ordem. Foi formado engenheiro civil na Escola de Engenharia de Porto Alegre, onde respirou os ares do pensamento industrialista que circulavam no Brasil desde o final do século XIX. No Brasil, pelo menos quatro escolas de engenharia funcionavam como lugares de sociabilidade e de circulação do pensamento industrialista: as Politécnicas de São Paulo e do Rio de Janeiro, a Escola de Minas de Ouro Preto e a Escola de Engenharia de Porto Alegre. Tanto a Politécnica de São Paulo quanto a escola de Porto Alegre tinham como anexos dois espaços para o ensino industrial, destinados à formação de trabalhadores: a Escola Mecânica e o Instituto Parobé, que mais tarde foram referências para o Centro Ferroviário de Ensino e Seleção Profissional (CFESP) e 
este para o SENAI. Montojos não chegou a estabelecer-se profissionalmente como engenheiro civil, mas, foi desse lugar que ele se relacionou com outros engenheiros que circulavam nos ambientes empresariais e governamentais envolvidos com a EP, entre os quais Roberto Simonsen, Euvaldo Lodi e Roberto Mange.

Já a condição de burocrata de Montojos é referente à sua longa permanência no Ministério da Educação e Saúde Pública (MESP). Montojos já estava no Governo Federal havia três anos quando o MESP foi criado, em 1930, permaneceu durante todo o período Vargas e retornou nos governos posteriores, saindo apenas no início da década de 1960. Essa estabilidade, em meio às turbulências políticas, deram a Montojos certa condição de depositário e de guardião da memória das ideias que circularam nas intensas disputas que culminaram na criação da rede de escolas técnicas e do SENAI em 1942. Uma regularidade na atuação de Montojos foi o esforço de racionalização da atuação do Estado na EP. Essa ênfase na racionalização, que se expressa em leis, diretrizes e estatutos, típica da conduta pública de Montojos, era algo equivalente ao que Weber (1987) definiu como predomínio da regra sobre o costume, os sentimentos e outros fatores de ordem pessoal, familiar ou privada.

Montojos engajou-se na EP e no ensino industrial e, nessa condição, foi tanto um educador quanto um memorialista. Não foi professor, mas foi educador. Seu lugar não era a sala de aula, o laboratório ou a oficina, mas, sua atuação não estava restrita aos gabinetes. Como dirigente do ensino industrial, Montojos frequentava as escolas técnicas e, como superintendente da CBAI, ele também frequentava as unidades do SENAI. Um de seus focos de atuação era a racionalização dos processos de seleção e de preparação dos gestores das unidades de ensino profissional, com ênfase na formação de professores.

A incumbência de representar o Governo Federal, em eventos internacionais e nacionais de EP, dava a Montojos a oportunidade de conhecer as experiências anteriores e elaborar uma linha de evolução da EP no Brasil. Evolução era uma ideia que circulava entre intelectuais brasileiros do início da República. A ideia vinha do darwinismo, mas também tinha forte conotação positivista, notadamente na ideia comteana ${ }^{2}$ de estágios do progresso

\footnotetext{
${ }^{2}$ Expressão referente à Auguste Comte (1789-1857) e sua lei dos três estágios do progresso humano.
} 
humano. Na escrita de Montojos existem textos sobre a evolução da EP no Brasil, nos quais ele critica a ausência de políticas de EP e ressalta a "pobreza de fatos" herdada.

"Pobreza de fatos" era a expressão sintética de Montojos para a precariedade institucional, a escassez de profissionais especializados e a ausência de métodos e de materiais próprios ao ensino das técnicas laborais. Consta em sua escrita que até então o Brasil tinha poucas experiências a serem consideradas. Um elemento dessa "pobreza de fatos" era a ausência de organicidade ou de um sistema nacional de EP: "o pouquíssimo existente era de iniciativa privada ou, quando muito, parcamente protegido por esmolas de soberanos ou seus propostos" (MONTOJOS, 1933, p. 11). O que Montojos salientava era a ausência do Estado e de políticas para a EP, para a infância e para a inclusão social da população pobre e o quanto a educação para o trabalho era marcada pela filantropia e dissociada de um projeto de desenvolvimento nacional, econômico e social.

Mas, na representação de Montojos, a "pobreza de fatos" na história da EP não era vinculada à igual pobreza de ideias. Montojos, em sua escrita memorialista, faz referências a homens do século XIX que foram autores de diversas propostas para a EP no país. Entre eles é citado o baiano Antônio Ferreira França (1771-1848), deputado constituinte de 1824, a quem "cabe a glória de ser quem primeiro cogitou do ensino profissional oficialmente organizado entre nós." (MONTOJOS, 1949, p. 11). Já em 1824, quando o setor primário preponderava na economia brasileira, França já indicava que a EP tinha de ser política pública, ação continuada do Estado. Outra ideia de França, de 1830, era a proposta de que "em cada distrito de 100 fogos houvesse uma escola de ensino elementar e outra de artes: os aprendizes que, de manhã, foram a uma, irão à outra à tarde." (MONTOJOS, 1949, p. 11). Ou seja: escola de tempo integral, com formação propedêutica em um turno e artes em outro.

Entre os citados por Montojos estão, também, Liberato Barroso (1830-1885), Tavares Bastos (1839-1875), Tarquínio de Souza Filho (1859-1908), João Alfredo Correia de Oliveira (1835-1919), Félix Ferreira (1841-1898), João Maurício Wanderley, Leôncio Carvalho (1847-1912), Rui Barbosa (1849-1923) e Manoel Dantas (1867-1924). Esses nomes, identificados por Montojos como pensadores da EP no século XIX, em boa parte atendiam ao requisito do intelectual stricto sensu, qual seja, o engajamento em acontecimentos e movimentos. Esses nomes eram de jornalistas, professores ou políticos; 
de intelectuais ligados em redes de sociabilidade, com propostas e manifestos, envolvidos com a circulação de ideias. Ao relacionar esses homens e suas ideias sobre a EP no século $\mathrm{XIX}$, Montojos destacava o modo de como eles elevavam o trabalho e os trabalhadores e os colocavam num lugar estratégico no processo de desenvolvimento nacional e, para isso, a importância de instituições públicas voltadas para a EP.

O fato é que, ao atuar como memorialista da EP, faltou ao engenheiro civil Montojos uma característica importante no trabalho do historiador: a alteridade no trato com as fontes. Montojos tinha noção da importância dos acontecimentos dos anos 1940 na história da EP brasileira e seu protagonismo nesse processo fez com que ele classificasse as experiências anteriores como "pobreza de fatos", de modo a relevar a riqueza de fatos com a qual ele estava envolvido. Montojos explora o passado, enriquece sua exposição, fortalece seus argumentos e de maneira positiva narra o presente e vislumbra o futuro da nação. A história contada por Montojos coloca-o como um divisor de águas entre o velho e o novo, entre a pobreza de fatos e a riqueza inaugural de fatos. Nesse sentido, é uma escrita com um narrador bem definido. O narrador está na trama e quer ser protagonista. Mas, isso não deslegitima a sua síntese. Afinal, a "pobreza de fatos" era fato. Montojos desqualificava o passado e a este contrapunha seu horizonte de expectativas. O horizonte representado na escrita de Montojos era de uma sociedade sem pobreza, sem desperdício, sem marginalidade social. Não há na escrita de Montojos palavras que o liguem ao taylorismo ou ao fordismo, assim como ele não evoca o mercado ou a empresa como referência, nem exalta a economia como centro da vida social.

A escrita de Montojos (1949) no texto "Evolução do Ensino Industrial no Brasil" permite um nexo com uma questão posta por Arendt sobre a ligação entre o passado e o futuro. Essa ligação é feita pelo homem, "que vive sempre no intervalo entre o passado e o futuro." (ARENDT, 2016, p. 36). Nesse texto, Montojos (1949) faz narrativas e propostas: no posto de diretor do ensino industrial e se coloca como o ponto de partida para um futuro rico em fatos. O protagonista quer livrar-se do passado e caminhar rumo a um futuro certo. O problema eram os limites do tempo presente de Montojos, com destaque para a resistência do empresariado industrial. 
A República brasileira surgiu um ano após formalizado o fim do trabalho escravo em lei sancionada pela princesa Isabel, que regia o país, enquanto seu pai, o imperador Pedro II, viajava ao exterior. O fim do trabalho escravo (1888) foi um ato emblemático, porque o Brasil era o último país ocidental a admitir a escravidão.

Surgida em 1889, foram necessários vinte anos para que a República brasileira inserisse na agenda do Governo Federal a formação do trabalhador nacional: republicano, urbano e industrial. Em 1909, o presidente Nilo Peçanha decretou a criação das dezenove Escolas de Aprendizes Artífices, uma em cada capital das unidades da federação. Mas, as Escolas de Aprendizes Artífices já nasceram defasadas, mesmo estando localizadas nas capitais e tendo como justificativa legal a necessidade de formação do trabalhador urbano e a integração social do proletariado. O decreto continha expressões cunhadas por Marx e por Darwin no século XIX, o "augmento constante da população das cidades exige que se facilite às classes proletarias os meios de vencer as dificuldades sempre crescentes da lueta pela existência”³.

Apesar de situadas nas capitais, as dezenove escolas que expressavam a primeira atenção republicana ao trabalho e ao trabalhador nacional não constituíam uma rede nacional, prevalecendo a desintegração e a falta de padrões no tocante aos cursos, aos métodos e aos materiais de ensino. Além disso, as escolas operavam em escala artesanal, tinham uma abrangência local ou regional, uma ênfase mais na moral do trabalho do que na formação técnica e seu público ainda era de crianças pobres e desvalidas.

O primeiro reconhecimento dessa defasagem das Escolas de Aprendizes Artífices veio em 1921 com a criação do Serviço de Remodelação do Ensino Profissional Técnico, comandado pelo engenheiro João Luderitz, também formado na Escola de Engenharia de Porto Alegre. As propostas apresentadas pelo Serviço de Remodelação incluíam a modernização e racionalização das Escolas de Aprendizes Artífices, incluindo a padronização dos currículos e edificações adequadas ao ensino da técnica. Também foi sugerida a industrialização das escolas, ou seja, prática que torna as escolas profissionais unidades produtivas de modo a cumprirem duas funções: permitirem o treino das técnicas de

3 Decreto n.o 7.566, de 23 de setembro de 1909. Disponível em: http://portal.mec.gov.br/setec/arquivos/pdf3/decreto 7566 1909.pdf. Acesso em: 11 fev. 2020. Neste e em outros trechos extraídos das fontes primárias é preservada a grafia segundo as normas da época. 
trabalho aprendidas e constituírem-se fonte de renda para os alunos pobres, de modo a conter a evasão escolar.

As propostas do Serviço de Remodelação não resultaram em mudanças efetivas, mas já sinalizavam para a urgência de instituições de EP capazes de atuarem com eficiência na formação do trabalhador industrial e urbano. A consequência prática da remodelação foi a criação de um órgão de inspeção às Escolas de Aprendizes Artífices, o que funcionou com certa padronização e gestão da atuação em rede.

Em 1927, um fato político relevante foi a sanção do Congresso Nacional ao projeto do deputado Fidélis Reis, que previa a oferta obrigatória do ensino profissional no país. A Lei Fidélis Reis, tal qual as propostas do Serviço de Remodelação, foi letra morta, isto é, não resultou de imediato na efetivação de políticas públicas ou em novas instituições de EP, mas foi um vetor para acontecimentos dos anos 1930 e 1940. Além disso, a novidade da lei era a obrigatoriedade da EP para todos e, não apenas, para os pobres.

O ano de 1927 marcou o início das atividades de Montojos no Serviço de Remodelação do Ensino Profissional Técnico e, também, de seus contatos com ideias angloamericanas que circulavam na educação brasileira. Nessa época, Anísio Teixeira estava em viagem pedagógica aos EUA e apresentou a Montojos o livro Métodos Americanos de Educação Geral e Técnica, do belga Ômer Buyse. A propósito, a obra de Buyse já havia sido apresentada a Anísio Teixeira em 1925 pelo educador escolanovista Carneiro Leão, ocasião em que Teixeira, aos 25 anos de idade, assumiu o comando da instrução pública na Bahia. Embora sem vínculos diretos com a EP, Anísio Teixeira fazia parte dos círculos de sociabilidade de Montojos, com Lourenço Filho, que também fazia apropriações na psicologia da aprendizagem anglo-americana e as fazia circular no Brasil.

Na década de 1930, com a chegada de Getúlio Vargas ao poder, foi criado o Ministério da Educação e Saúde Pública (MESP) e o então Serviço de Remodelação do Ensino Profissional Técnico foi transformado em Inspetoria do Ensino Profissional Técnico, ligada ao MESP e, não mais, ao Ministério da Agricultura, Indústria e Comércio. Montojos foi nomeado inspetor-geral. As Escolas de Aprendizes Artífices passaram igualmente à alçada do MESP.

Em 1932, um grupo de intelectuais, preocupados em elaborar um programa de política educacional amplo e integrado, lançou o Manifesto dos Pioneiros da Educação Nova, 
redigido por Fernando de Azevedo e assinado por ele e outros educadores, entre eles Anísio Teixeira e Lourenço Filho. Nesse período, no âmbito do Governo Federal, houve significativa movimentação que visava à constituição e instituição de novo ensino industrial. $\mathrm{O}$ ano de 1934 guarda dois marcos desse processo: a promulgação da Constituição Federal, cuja peculiaridade uniformizadora deliberou à União a responsabilidade de delinear as diretrizes educacionais para todo o território nacional e a nomeação, pelo ministro Gustavo Capanema, de uma comissão para a reorganização do ensino industrial. O trabalho dessa comissão culminou em 1942 com o início de funcionamento do SENAI e das Escolas Técnicas Federais.

De 1934 até 1942 as relações entre o MESP, o Ministério do Trabalho, Indústria e Comércio (MTIC) e representações do empresariado industrial foram intensificadas. Em 1937 o ministro Gustavo Capanema reformou o MESP e transformou a Superintendência do Ensino Profissional em Divisão do Ensino Industrial, continuando Montojos à frente. "Ou seja, mudaram o ambiente político, o nome e a estrutura do Ministério da Educação e Saúde, e Montojos não apenas permaneceu, como foi promovido, passando de superintendente a diretor da Divisão do Ensino Industrial." (PEDROSA; SANTOS, 2015, p. 6).

A partir de 1942 o ensino industrial expandiu-se aceleradamente, tendo em vista a conjuntura internacional e o crescimento econômico nacional dela decorrente. A Segunda Guerra propiciou essa aceleração por dificultar a importação de produtos industrializados, ao mesmo tempo em que gerava oportunidades para exportação de produtos industriais básicos: minério, ferro, aço e outros. Ainda nesse ano, os EUA entraram na guerra e, em 1943, o Brasil declarou apoio aos países aliados, o que proporcionou uma aproximação com os EUA, com reflexos no crescimento industrial brasileiro.

Esse crescimento econômico, industrial e urbano exigiu a formação de nova cultura empresarial e de novo tipo de trabalhador: especializado, disciplinado e apto à gerência. Como isso, Getúlio Vargas baixou o decreto-lei que criava o SENAl ${ }^{4}$ e a rede de escolas técnicas federais 5 . Para atender às pressões dos empresários industriais foi delegada à Confederação Nacional da Indústria (CNI) a gestão do SENAI, ficando as escolas técnicas sob responsabilidade do MESP.

\footnotetext{
${ }^{4}$ Decreto-Lei n.o 4.048, de 22 de janeiro de 1942.

${ }^{5}$ Decreto-Lei n.o 4.127, de 25 de fevereiro de 1942.
} 
Para responder à demanda pela mão de obra industrial, as lideranças do empresariado - CNI e suas federações, com destaque para a Federação das Indústrias do Estado de São Paulo (FIESP) - e setores do governo, em especial o MESP ${ }^{6}$ e o MTIC, começam a definir novo tipo de EP, prioritariamente, o ensino industrial7: novas instituições de ensino, novo tipo de público (selecionado pela psicotécnica e, não mais, os pobres e desvalidos) e nova didática (séries metódicas). Essas ações representavam a mudança do telos do ensino profissional, que a partir de então passava a ser destinado à preparação de trabalhadores e técnicos para o mercado de trabalho, com recrutamento amplo e, não mais apenas, os pobres, órfãos e desvalidos.

Nesse período o Brasil já tinha aproximações sistemáticas com os EUA, embora ainda inexistissem acordos formais. Essa aproximação com os EUA decorreu de vários fatores. Um deles era que, desde a proclamação da República, já havia uma mudança do foco das elites brasileiras, que passaram a dar atenção às novidades que vinham do Norte. Nos anos 1920, Anísio Teixeira permaneceu por duas longas temporadas na Universidade da Colúmbia e abriu espaços para outros intelectuais da EP realizarem visitas técnicas e pedagógicas ou cursarem mestrado nos EUA nos anos 1930. Monteiro Lobato também esteve nos EUA de 1927 a 1931, na condição de adido comercial do Brasil. Mas, além desse fluxo de intelectuais brasileiros aos EUA, havia outro fator nessa aproximação. Nos anos 1930, a Europa já lidava com muitos problemas que culminaram na Segunda Guerra: o fechamento era inevitável. Enquanto isso, do outro lado do Atlântico, os EUA saíam fortalecidos da crise de 1929: se a Europa se fechava, os EUA tornavam-se mais expansionistas.

Tudo isso reverberava na EP e, nesse período, já havia circulação de técnicas e de técnicos anglo-americanos no ensino industrial no Brasil:

\footnotetext{
${ }^{6}$ Com a Reforma ocorrida em 1937, o Ministério da Educação e Saúde Pública passou a denominar-se Ministério da Educação e Saúde (BRASIL, 1937a).

${ }^{7}$ Ensino industrial é um segmento específico da educação profissional, tal qual o ensino agrícola ou o ensino comercial. O foco do ensino industrial é a indústria, assim como o do ensino comercial é o comércio. Na indústria a atividade é produtiva, isto é, consiste na transformação de materiais em produtos e mercadorias. Essa especificidade da indústria cria singularidades tanto para o que se ensina como para os modos de ensinar e de aprender. Além disso, a indústria que proliferava no Brasil dos anos 1940 era muito dependente do trabalho vivo e seu crescimento gerava postos de trabalho e emprego, o que exigia um ensino industrial também em ampla escala.
} 
depois da tentativa frustrada de obter professores alemães, em 1936, e da contratação de professores suíços para as escolas industriais, em 1941/42, o Ministério da Educação voltou-se para os Estados Unidos como fonte de assistência técnica para esse importante ramo do ensino, estratégico para a política industrialista do Estado Novo. (FALCÃO; CUNHA, 2009, p. 151.)

Mas a culminância dessa aproximação com os EUA veio nos anos 1940 com a criação das escolas técnicas e do SENAI, em 1942. Essa criação fez o Brasil deparar-se com a necessidade de professores específicos para esse tipo de ensino; nas palavras de Montojos, professores de oficina ou professores de cultura técnica. Com a Europa em guerra e, posteriormente, envolvida com as tarefas de sua reconstrução, o Brasil, pressionado pela demanda de trabalhadores e técnicos para a indústria, foi buscar referências nos EUA.

Como solução para o necessário aprimoramento técnico e pedagógico, que visava à transformação dos instrutores em educadores, surgiu em 1946 a Comissão BrasileiroAmericana de Educação Industrial. Como Montojos era o diretor do ensino industrial, ele passou também a ser superintendente da CBAI que existiu de 1946 a 1963.

\begin{abstract}
Uma das maiores contribuições que a CBAI trouxe à causa do progresso industrial de nosso país foi, sem dúvida, a introdução, em nosso meio, do chamado método $\mathrm{TWl}^{8}$. Embora não faça ele, de maneira formal, parte do ensino industrial tal como geralmente é este último encarado, concorre, entretanto, para a mesma finalidade que é a de aumentar a produção industrial do país. (FONSECA, 1961, p. 572.)
\end{abstract}

Montojos foi superintendente da CBAI por dois períodos, sendo o dirigente que permaneceu por mais tempo à sua frente. Como diretor do ensino industrial, participou diretamente de inúmeras atividades relacionadas à constituição e instituição do novo ensino industrial, com destaque na formação de professores de cultura técnica.

\title{
3 A pedagogia dos trabalhos manuais
}

A assim chamada pedagogia dos trabalhos manuais era um assunto que circulava no Brasil dos anos 1920, 1930 e 1940, sintonizada com o movimento pela Escola Nova. Havia nessa pedagogia dos trabalhos manuais uma perspectiva de formação ampla do trabalhador urbano, bem além da técnica e das habilidades manuais.

\footnotetext{
${ }^{8} \mathrm{O}$ Training Within Industry - TWI foi um programa de treinamento rápido e intensivo desenvolvido nos anos 1940 nos EUA, no contexto economia de guerra. O sucesso do programa na preparação de operários em regime de urgência fez dele uma referência replicada em outros países, inclusive no Brasil.
} 
Essa atenção aos trabalhos manuais e sua relação com a aprendizagem tinham dois motivos principais para eles estarem postos. Um motivo estava na forte herança da cultura escravista na divisão social e técnica do trabalho, nas relações cotidianas e no imaginário das pessoas. A casa-grande, habitat da superioridade social dos senhores, fomentou o preconceito e a antipatia em relação ao trabalho manual e à técnica. O fim da escravidão já estava decretado, mas os estigmas, estereótipos e caricaturas dos trabalhadores e do trabalho manual insistiam em permanecer nas representações sociais.

O problema é que essa aversão ao trabalho não era compatível com uma sociedade industrial, urbana e de massas, tal qual configurada no horizonte de expectativas dos engenheiros industrialistas da época, entre os quais Montojos. Era, pois, necessário fazer a educação moral e técnica do trabalho e essa era uma das razões dessa pedagogia dos trabalhos manuais.

Outra razão era a circulação dos ideais da Escola Nova no Brasil. O escolanovismo foi um movimento de renovação que surgiu no final do século XIX, em decorrência de insatisfações com a escola existente (chamada de tradicional): a escola do silêncio e da atenção, da disciplina e do controle, panóptica e enciclopédica, centrada no ensino, no professor e confinada na sala de aula. Esse movimento de renovação da escola surgiu em países europeus e nos EUA quase que simultaneamente e repercutiu, rapidamente, no Brasil. Nos EUA, o movimento pela Escola Nova ganhou dois importantes aportes: o pragmatismo e sua ênfase na prática e a psicologia experimental e seu foco na aprendizagem.

Mas, o problema do Brasil dos anos 1920 nem chegava a ser o anacronismo da escola, mas a ausência da escola. A escola pública brasileira foi tardia. Foi somente nos anos 1940 que o Brasil veio a constituir sistemas nacionais de educação pública. Os filhos das elites eram enviados para as escolas privadas e religiosas, mas, eram poucas e precárias as escolas destinadas ao povo. Para os escolanovistas era urgente instituir no Brasil a escola pública, laica e de boa qualidade: sem ela não haveria progresso nem democracia. É por isso que no Brasil o movimento pela instituição da escola foi, simultaneamente, pela renovação escola. Foram, os escolanovistas de 1932, os primeiros na história do Brasil a lançar um manifesto público, dirigido ao governo e à sociedade, a favor da escola pública. 
E havia estreita sintonia entre a renovação da escola, as atividades práticas e os trabalhos manuais. Era pedagogicamente desejável e compatível a presença da oficina e do laboratório dentro da escola e as atividades práticas e manuais eram um modo de torná-la ativa, envolvente e interessante, com reflexos na aprendizagem.

No Brasil modernista dos anos 1920, a renovação da escola por meio da pedagogia dos trabalhos manuais mobilizava a atenção de importantes nomes da educação, entre os quais Manoel Pena ${ }^{9}$, Lourenço Filho, Corinto da Fonseca ${ }^{10}$ e o próprio Montojos. Lourenço Filho, ao prefaciar "A escola ativa e os trabalhos manuais", livro de Corinto da Fonseca, afirmou:

se há trabalho intelectual e trabalho manual, [...] não há dúvida alguma em que o trabalho intelectual isolado leva às aberrações do verbalismo, da formação intelectualista pura, sem finalidade para as atividades normais, por um lado, e sem assento, por outro, na afetividade criadora e motilidade natural da criança. Donde, ser o centro de irradiação da moderna didática o próprio trabalho com as mãos. (FONSECA, C., 1929, p. 6.)

Montojos tinha particularidades em relação aos intelectuais de sua geração. Uma das diferenças pode ser identificada em comparações com Anísio Teixeira ou Lourenço Filho, situados na categoria dos "grandes intelectuais" (MAGALHÃES, 2016). Tanto Teixeira quanto Lourenço Filho eram homens eruditos, além de virem das ciências jurídicas sociais. Montojos vinha da engenharia civil. Era um intelectual, mas, não necessariamente, um erudito. Ele não era um homem de ideias próprias e de elaboração sofisticada, tal qual Teixeira ou Lourenço Filho, mas tinha capacidade refinada de apropriação, de elaboração de suas próprias sínteses e de fazer as ideias circularem em seu ambiente de atuação na EP.

A apropriação, no sentido aqui referido a Montojos, vem de Chartier (1991), para quem uma apropriação é uma ressignificação, uma mudança tanto no sujeito que apropria como na ideia apropriada. Apropriação é, pois, reelaboração. Essa característica de Montojos como um intelectual apropriador tem relação com sua longeva atuação no MESP, na EP e no ensino industrial. Montojos foi um testemunho ou uma consciência das ideias

\footnotetext{
${ }^{9}$ Manoel Penna (1871-1939) atuou na instrução pública em Minas Gerais e foi referência na pedagogia dos trabalhos manuais. Entre suas publicações constam: "Trabalho Manual Escolar: Alinhavos" (1915), "Exposição escolar" (1920), "O Ensino technico na escola primária" (1928). Em 1933 publicou na Revista de Ensino de Minas Gerais, consolidando as suas ideias no compêndio "Trabalhos Manuaes Escolares" (DUARTE, 2017).

${ }^{10}$ Corinto da Fonseca (1882- ?) foi professor e diretor de escola, fundou a "Bolsa Escolar Irineu Marinho". É autor de diversas obras, dentre as quais: "O ensino profissional no Brasil" (1916); "O ensino profissional em São Paulo"; “A Escola Ativa e os trabalhos manuais” (1929). (HOELLER; DAROS, 2014).
} 
acerca da EP que circularam no âmbito do Governo Federal nas várias décadas em que ele lá esteve e foi, também, um importante elo entre a Escola Nova e a EP. Ele foi importante, ao lado de Roberto Mange e Lourenço Filho, na circulação do ideário escolanovista na EP. A pedagogia dos trabalhos manuais é típica dessa atuação característica de Montojos. Ele não é um elaborador dessa concepção, tal qual Fonseca, Pena ou Lourenço Filho, mas foi ele quem circulou a proposta no ambiente da EP e esse foi, na perspectiva de Sirinelli, um importante trabalho do intelectual.

Montojos, ao trazer o trabalho manual em seus escritos, discorre sobre a importância deste para a saúde física, mental e para o desenvolvimento intelectual da criança desde tenra infância e enfatiza: "nada mais cabível que se cuidar do trabalho manual na educação dos homens ainda nos seus primeiros anos, seja com o fim de se lhes desenvolverem as qualidades físicas, intelectuais ou morais." (MONTOJOS, 1949, p. 7).

Ele criticava o preconceito existente com relação às atividades manuais no Brasil. Segundo ele, a ênfase na cultura livresca era um dos traços da assim chamada pedagogia tradicional.

A velha pedagogia, eivada de preconceitos de todo em todo contrários à natureza, ditava leis, hoje verificado, antes serviam para formar autômatos que homens propriamente ditos, incapazes de entenderem a vida como esta deve ser exercida ou, melhor, vivida na plenitude das suas faculdades e funções todas correlatas entre si. Assim, eram subentendidas uma educação literária, uma educação científica e, entre outros muitos processos educativos que se chamavam, arbitrariamente, do espírito, falava-se, afinal, em tom depreciativo, de uma educação profissional, separada por fortes barreiras hierárquicas das primeiras enumeradas, por isso que esta só se referia aos trabalhos feitos apenas com as mãos. (MONTOJOS, 1949, p. 7.)

Montojos pontuava que a evolução dos conhecimentos se tem encarregado de corrigir tais erros de concepções e apontava o trabalho manual como um dos pilares para a educação escolar: "hoje se vem compreendendo que ler, estudar e ouvir lições, ao mesmo tempo que se executam obras manuais, constituem a verdadeira educação integral, que é a derivante do exercício das mãos pelo espírito e do espírito pelas mãos." (MONTOJOS, 1949, p. 7).

A relação entre a mão e o cérebro exposta por Montojos revela apropriações das ideias de John Dewey e de Adolph Ferrière, ambos ligados à Escola Nova e defensores da autonomia dos alunos e da experiência da criança como base para uma educação intelectual 
pela utilização do trabalho manual. As críticas de Montojos à velha pedagogia remetia-o à nova pedagogia que já estava em voga no país e que já era defendida por Lourenço Filho em seu livro de 1930, "Introdução ao estudo da Escola Nova". O ideal da Escola Nova, afirma Lourenço Filho:

é a liberdade interior, a formação de dentro para fora. $O$ ideal da velha pedagogia era a autoridade externa, a imposição de normas e a transmissão de conhecimentos de fora para dentro. Era a escola da autoridade. Autoridade do mestre, a cujo espírito o discípulo deveria amoldar-se, autoridade do texto e máxima autoridade, quando este fosse único... Antes, a pedagogia era a condução por mão estranha. Agora, toda educação significa, em última análise, autoeducação. (MINISTÉRIO DA EDUCAÇÃO, 2010, p. 62.)

Autoeducação é uma perspectiva oriunda do método de Maria Montessori que constitui um exemplo dos ideais da Escola Nova, que enfatizava a importância da infância e da liberdade da criança em aprender aquilo que para ela é razão de sentido, aproveitando assim sua capacidade inata de querer aprender (apud SANTOS, 2003). Essa idealização de uma pedagogia moderna, segundo Lourenço Filho (1930), era "um conjunto de doutrinas e princípios tendentes a rever, de um lado, os fundamentos da finalidade da educação, e de outro, as bases de aplicação ciência à técnica educativa" (MINISTÉRIO DA EDUCAÇÃO, 2010, p. 61).

Montojos estava sintonizado com os ideais da Escola Nova, defendendo a aplicação da nova pedagogia na educação em geral e no ensino profissional em particular. Para reforçar seu posicionamento, ele salientava a efetivação de nova e "racional concepção pedagógica", uma concepção que enfatizava a importância do trabalho manual como método. Montojos destaca que o norte da Europa, EUA e mais tardiamente o sul da Europa foram os vetores desse movimento. Interessante notar como ainda na segunda metade do século XIX os acontecimentos pioneiros em educação já começaram a ocorrer fora da Europa, principalmente nos EUA.

Montojos recorre ao francês Gustave Le Bon para salientar a crítica ao preconceito contra o trabalho manual:

A causa principal da nossa antipatia pelo trabalho manual e por tudo que com ele se pareça não é tanto pelo esforço que aquele requer como pelo desprezo que inspira. Este sentimento é um dos que mais têm precipitado a nossa atual decadência industrial e econômica. Entre os latinos, o mais ínfimo clérigo, o mais humilde empregado, o mais modesto professor se julgam de casta superior a de um industrial ou de um artífice, embora estes 
ganhem mais e executem trabalhos que exigem mais inteligência. (MONTOJOS, 1949, p. 8.)

Le Bon era francês e Montojos buscava nele referências para a defesa da educação das mãos e pelas mãos, da educação pelos trabalhos manuais, visando à "autoeducação". Montojos salientava as expressões do escárnio pelas atividades manuais: antipatia, desprezo, inferioridade. Ele destaca o quanto a crítica de Le Bon era apropriada ao Brasil, "onde impera ainda, o preconceito hereditário de descendentes de senhores e a revolta radical dos filhos e netos de escravos contra o trabalho manual." (MONTOJOS, 1949, p. 8). Essa antipatia pelos trabalhos manuais tornava difícil a missão dos dirigentes e educadores de criar a cultura laboral e técnica necessária ao crescimento industrial e econômico do país. Numa sociedade em que o trabalho manual era destinado aos escravos, "essa característica 'contaminava' todas as atividades que lhes eram destinadas, as que exigiam esforço físico ou utilização das mãos." (CUNHA, 2005c, p. 16).

Em seus argumentos sobre a importância do trabalho manual na educação dos novos, Montojos aborda o "brinquedo" como meio de desenvolvimento intelectual; uma forma de aprendizagem baseada na evolução afetiva da criança, ou seja, por meio de seu interesse natural. Para isso, recorre a interlocutores como Rousseau, que, "aconselhava o trabalho manual como o único capaz de tornar o homem independente." (apud MONTOJOS, 1949, p. 8). Cita também Braunschwing, que considera que "o brinquedo do ponto de vista biológico e social se nos aparece como um fato importante que permite classificar os seres na hierarquia das espécies." (apud MONTOJOS, 1949, p. 8). Ou seja, o brinquedo humano que expressa a diferença qualitativa entre homens e animais. Por fim, cita um dos pioneiros da pedagogia ativa, Adolphe Ferrière, que "tece interessantes conceitos sobre o brinquedo que envolve a ideia do divertimento e liberdade absoluta e a de trabalho que abrange a de utilidade e coação." (apud MONTOJOS, 1949, p. 9).

Montojos salientava que o brinquedo estimula a curiosidade, a iniciativa, a imaginação, a invenção e tem um papel importante no desenvolvimento infantil. Ele justifica essa ênfase com uma frase de Herbert Spencer, que "afirma que qualquer coisa, por mínima que seja, tem algum valor desde que nos prenda a atenção." (MONTOJOS, 1949, p. 9).

Para Montojos (1949, p. 9):

Todas essas opiniões vêm em abono do papel importantíssimo que essa coisa aparentemente simplíssima, como dissemos - o brinquedo - atingiu 
na moderna pedagogia, a ponto de merecer que se criem doutrinas a seu respeito e se façam consequentes críticas e comentos em páginas e, até, em livros notáveis. [...] A verdade indisputável é que o "brinquedobrinquedo" ou o "brinquedo-trabalho" são como que o vestíbulo ao preparo integral do homem.

\section{Considerações finais}

O artigo teve como objetivo situar a atuação, a escrita e as representações de Montojos acerca da EP e, de modo particular, do ensino industrial brasileiro, no período de 1920 a 1950. O período de atuação de Montojos no ensino industrial remonta a um momento de constituição, instituição e expansão deste ramo de ensino, tendo em vista o crescimento econômico e industrial pelo qual passava o Brasil. Sua atuação remete a uma etapa relevante na história do país, quando este se aproximou dos EUA em busca de referências para formação de profissionais para a indústria em expansão. Dessa aproximação com ideias e ações anglo-americanas na EP, em especial no ensino industrial, surgiu o acordo denominado CBAI.

Montojos permaneceu por várias décadas em posições estratégicas na gestão do ensino industrial num período de instabilidade política no Brasil. Ele foi integrante do MESP de 1927 a 1961, ocupando cargos de confiança de distintos ministros da Educação. Sua presença na EP do Governo Federal foi concomitante à constituição, instituição e expansão da educação profissional e do ensino industrial, seja no tocante ao número de escolas e de matrículas, à qualidade do ensino e, principalmente, em relação ao prestígio social dessa modalidade de ensino. Como mencionado ao longo do artigo, todo esse crescimento pôs exigências de racionalização e regimentação e Montojos foi protagonista em todo esse processo no qual, a partir de 1930, surgiu um olhar estratégico para o ensino profissional e técnico, resultando em políticas públicas, nova institucionalidade e nova pedagogia.

Montojos faz parte da história dos intelectuais brasileiros da EP e de importantes movimentos no âmbito da educação nacional; foi protagonista em significativos acontecimentos durante sua atuação e seus círculos de sociabilidade incluíam outros destacados protagonistas da política e da educação à época.

Montojos esteve presente em quase todas as unidades da federação brasileira em seu trabalho de visitar escolas e acompanhar trabalhos realizados na EP. Foi Montojos quem organizou o primeiro curso de direção de escolas técnicas e industriais no Brasil (FONSECA, 
1961). Além dessa atuação direta, ele deixou uma série de escritos em forma de discursos, relatórios, artigos ou livro. Viajou para diversos países, entre eles os EUA, e uma das finalidades era a apropriação de ideias, práticas e projetos e fazê-los circularem no Brasil, ou seja, Montojos aparecia como uma das pessoas ativas e de relevância nas articulações quanto à EP na época.

No que diz respeito à participação e à posição de Montojos nas disputas entre empresários industriais, intelectuais e homens de governo no tocante à constituição e instituição do novo ensino industrial, salienta-se que ele participou de vários grupos de trabalho para elaboração de projetos e atuou diretamente nas negociações entre governo e empresários industriais na definição das redes de ensino nos anos 1930 e 1940, em especial na criação do SENAl e das escolas técnicas federais em 1942.

Fonseca (1961) afirma que é difícil dissociar o ensino industrial da figura de Montojos, visto que sua ação foi marcante na fase mais ativa e de maiores progressos deste ramo de ensino. Montojos era industrialista, integrante do Governo Federal, um burocrata, no sentido weberiano, um intelectual formulador de políticas públicas para a EP.

Ele era homem de confiança do ministro Gustavo Capanema. Na EP defendia: a constituição de um sistema nacional de EP, uma educação de boa qualidade, gratuita e escola de tempo integral, além de política de apoio estudantil com a industrialização da escola, a escola sindical, a plena formação de professores, bem como, sua rigorosa seleção. Foi um intelectual engajado e que interferia no debate educacional do país, lidava com ideias e relacionava-as às causas que defendia, sendo ele, de acordo com Sirinelli (1966), um importante elo na circulação de ideias.

E quanto à posição de Montojos em face das ideias anglo-americanas que circulavam no Brasil no período de sua atuação, destaque-se que ele fora protagonista na definição do primeiro acordo entre Brasil e EUA para o ensino industrial, cujo principal objetivo era a capacitação de professores. Ou seja, Montojos foi um dos vetores da circulação de ideias anglo-americanas no Brasil.

Convém destacar que, naquele período, a demanda por professores de oficina ou de cultura técnica, que tivessem competência para a função de educador era uma necessidade. Em diversas ocasiões, Montojos abordava a situação do ensino precário no 
país, ocasionado pela ausência de docentes capacitados, ressaltando a urgência na adequada capacitação dos professores e mestres. Na direção da CBAI pôde colocar em prática um dos seus objetivos, que era a capacitação de professores.

Na direção da CBAI, Montojos teve sua atuação marcada por ações que promoviam a transferência de conhecimento dos EUA para o Brasil, o intercâmbio entre diretores do ensino industrial, visitas às diversas escolas espalhadas pelo país e envio de diretores, professores e técnicos brasileiros para os EUA para cursos de capacitação e aperfeiçoamento e cursos intensivos de aperfeiçoamento no Brasil. Note-se, ainda, na execução de sua função como superintendente da CBAl e diretor do ensino industrial, sua preocupação com a didática, com os instrumentos e técnicas facilitadores do aprendizado e da seleção, por intermédio da orientação educacional e profissional, direcionada aos alunos do ensino industrial.

As elaborações de Montojos sobre a pedagogia dos trabalhos manuais também caracterizam uma circulação de ideias escolanovistas nos ambientes da EP. Embora não tenha figurado como um dos signatários do Manifesto de 1932, Montojos pertencia aos círculos escolanovista e era conviva de Lourenço Filho e de Roberto Mange.

\section{REFERÊNCIAS BIBLIOGRÁFICAS}

ARENDT, H. Entre o Passado e o Futuro. 8. ed. São Paulo: Perspectiva, 2016.

BRASIL. Lei no 378, de 13 de janeiro de 1937. Dá nova organização ao Ministério da Educação e Saúde Pública. Rio de Janeiro, 1937a. Disponivel em: https://www.planalto.gov.br/ccivil_03/leis/19301949/I0378.htm. Acesso em: 02 dez. 2018.

CUNHA, L. A. Ensino de ofícios artesanais e manufatureiros no Brasil escravocrata. 2. ed. Brasília: Unesp, 2005.

CHARTIER, R. O mundo como representação. Estudos Avançados, São Paulo, v. 5, n. 11, p. 173-191, jan./abr. 1991.

DUARTE, S. R. "Educar as mãos para descobrir o mundo": a proposta do professor Manoel Penna para o ensino de Trabalhos Manuais (1906 -1934). 2017. Dissertação (Mestrado em Educação Tecnológica) - Cefet-MG, Belo Horizonte, 2017.

FONSECA, C. D. A escola ativa e os trabalhos manuais. 2. ed. v. 8, São Paulo: Melhoramento, 1929.

FONSECA, C. S. D. História do Ensino Industrial no Brasil. v. 1 e 2. Rio de Janeiro: Escola Técnica Nacional, 1961. 
FALCÃO, L. Q.; CUNHA, L. A. Ideologia, Política e Educação: a Cbai (1946/1962). Revista Contemporânea de Educação, Rio de Janeiro, v. 4, ISSN 1809-5747. Disponível em: https://revistas.ufrj.br/index.php/rce/article/view/1579. Acesso em: 3 jun. 2017.

GOMES, A. D. C. Essa Gente do Rio: Modernismo e Nacionalismo. 1. ed. Rio de Janeiro: Fundação Getúlio Vargas, 1999.

GOMES, A. D. C.; HANSEN, P. S. (Org.). Intelectuais mediadores: práticas culturais e ação política. 1. ed. Rio de Janeiro: Civilização Brasileira, 2016.

HOELLER, S. A. D. O.; DAROS, M. D. D. Trabalhos manuais no ensino primário e no ensino profissional para a construção da nação laboriosa: proposições de Orestes Guimarães e Corinto da FonsecaBrasil, anos de 1920. In: X Anped Sul. Anais..., Florianópolis, out. 2014.

LOURENÇO FILHO, M. B. Introducção ao estudo da Escola Nova. São Paulo: C.ia Melhoramentos, 1930. Bibliotheca da Educação, v. XI.

LOURENÇO FILHO, M. B. Conceito de aprendizagem - definição de aprendizagem comercial semelhanças entre aprendizagem no comércio e na indústria. Parecer solicitado pelo Senac. Rio de Janeiro, 1949. Acervo CPDOC / FGV - Centro de Pesquisa e Documentação de História Contemporânea do Brasil.

MAGALHÃES, J. Intelectuais e a história da educação em Portugal e Brasil. Cadernos de História da Educação. v. 15, n. 1, p. 299-322, jan./abr. 2016.

MINISTÉRIO DA EDUCAÇÃO. Coleção Educadores MEC: Lourenço Filho. Domínio Público, São Paulo, 2010. Disponível em: <http://www.dominiopublico.gov.br/download/texto/me4706.pdf>. Acesso em: 15 jun. 2018.

MONTOJOS, F. Ensino Industrial. Rio de Janeiro: MES/Cbai, v. 5, 1949.

PEDROSA, J. G.; SANTOS, O. G. D. Agentes do Ensino Industrial no Brasil (1920-30-40) e suas referências internacionais: Europeísmo e Americanismo. Cadernos de História da Educação, v. 13, p. 313-334, jan./jun. 2014.

PEDROSA, J. G.; SANTOS, O. G. D. Atuação de Francisco Montojos na Constituição e na Instituição do Novo Ensino Industrial Brasileiro (1934-1942). Revista Educação \& Tecnologia, Curitiba, n. 13, 2015.

SIRINELLI, J. Os intelectuais. In: RÉMOND, R. Por uma História Política. 2. ed. Rio de Janeiro: UFRJ/FGV, 1996.

WEBER, M. Conceitos básicos de Sociologia. São Paulo: Moraes, 1987. 